\title{
COSMIC project: consensus on the objectives of the metabolic syndrome in clinic
}

This article was published in the following Dove Press journal: Diabetes, Metabolic Syndrome and Obesity:Targets and Therapy

Juan Pedro-Botet,' Juan F Ascaso, ${ }^{2,3}$ Vivencio Barrios, ${ }^{4,5}$ Alejandro De la Sierra, ${ }^{6}$ Javier Escalada, ${ }^{7,8}$ Jesús Millán, ${ }^{9}$ Jose M Mostaza, ${ }^{10}$ Pablo PérezMartínez, ${ }^{8,11}$ Xavier Pintó, 8,12 Jordi Salas-Salvadó, ${ }^{8,13}$ Pedro Valdivielso ${ }^{14}$

'Lipids and Vascular Risk Unit, Hospital del Mar, Universitat Autònoma de Barcelona, Barcelona, Spain; ${ }^{2}$ Endocrinology and Nutrition Service, Hospital Clínico, Universitat de Valencia, Valencia, Spain; ${ }^{3}$ NCLIVA Research Institute, Diabetes and Metabolic Diseases Ciber (Networked Biomedical Research Centres - CIBERDEM), Carlos III, Valencia, Spain; ${ }^{4}$ Cardiology Service, Hospital Universitario Ramón y Cajal, Universidad de Alcalá, Madrid, Spain; ${ }^{5}$ Department of Medicine, Universidad Católica de Murcia (UCAM), Murcia, Spain; 'Internal Medicine Service, Hospital Mutua de Terrassa, Department of Medicine, Universidad de Barcelona, Spain; ' Department of Endocrinology and Nutrition, Clínica Universitaria de Navarra, IdiSNA; ${ }^{8} \mathrm{CIBEROBN}$ "Physiopathology of Obesity and Nutrition", Carlos III Health Institute, Spain; 'Lipid Unit, Department of Internal Medicine, Hospital Universitario General Gregorio Marañón, Universidad Complutense, Madrid, Spain; ${ }^{10}$ Lipid and Arteriosclerosis Unit, Internal Medicine Service, Hospital Carlos III, Madrid, Spain; "'Lipid and Arteriosclerosis Unit, Hospital Universitario Reina Sofía, IMIBIC/University of Cordoba, Cordoba, Spain; ${ }^{12}$ Lipids Unit, Department of Internal Medicine Hospital Universitario de Bellvitge, Universidad de Barcelona, Barcelona, Spain; ${ }^{13}$ Nutrition Unit, Hospital Universitari Sant Joan de Reus, Department of Biochemistry and Biotechnology, Universitat Rovira i Virgili; ${ }^{14}$ Internal Medicine Service, Department of Medicine and Dermatology, Hospital Universitario Virgen de la Victoria, Málaga Biomedicine Institute (IBIMA), Universidad de Málaga, Málaga, Spain

Correspondence: Juan Pedro-Botet Lipid and Vascular Risk Unit, Hospital del Mar. Passeig Marítim, 25-29, 08003 Barcelona, Spain Email JPedrobotet@parcdesalutmar.cat

\begin{abstract}
Metabolic syndrome (MetS), a disorder with a high and growing prevalence, is a recognized risk factor for cardiovascular disease (CVD) and type 2 diabetes. It is a constellation of clinical and metabolic risk factors that include abdominal obesity, dyslipidemia, glucose intolerance, and hypertension. Unfortunately, MetS is typically underrecognized, and there is great heterogeneity in its management, which can hamper clinical decision-making and be a barrier to achieving the therapeutic goals of CVD and diabetes prevention. Although no single treatment for MetS as a whole currently exists, management should be targeted at treating the conditions contributing to it and possibly reversing the risk factors. All this justifies the need to develop recommendations that adapt existing knowledge to clinical practice in our healthcare system. In this regard, professionals from different scientific societies who are involved in the management of the different MetS components reviewed the available scientific evidence focused basically on therapeutic aspects of MetS and developed a consensus document to establish recommendations on therapeutic goals that facilitate their homogenization in clinical decision-making.
\end{abstract}

Keywords: cardiovascular prevention, diabetes prevention, insulin resistance, hypertension, dyslipidemia, obesity

\section{Introduction}

Metabolic syndrome (MetS) is defined as the aggregation of a set of risk factors in a single individual which can lead to the development of cardiovascular disease (CVD) and type 2 diabetes mellitus (T2DM), with insulin resistance (IR) being the pathogenic link. This may be conditioned by genetic but mainly exogenous factors, including abdominal obesity and physical inactivity. Because of this, the clinical phenotype of MetS appears years after IR, and its prevalence is proportional to age of the population and the presence of aggravating factors.

Among the metabolic alterations associated with MetS, the following stand out: 1) dyslipidemia, mainly hypertriglyceridemia, a decrease in high-density lipoprotein (HDL) cholesterol, the presence of small and dense low-density lipoprotein (LDL) particles, together with a plasma increase in remnant triglyceride-rich lipoprotein particles and free fatty acids, and postprandial hyperlipidemia; 2) hyperglycemia or diabetes; and 3) arterial hypertension. These alterations, together with abdominal obesity, are the established parameters for the diagnosis of MetS. ${ }^{1}$ The diagnostic criteria established by different scientific societies and groups of experts are shown in Table $1 .^{2-5}$ Other alterations such as non-alcoholic fatty liver, hyperuricemia or gout, 
Table I Criteria proposed by different international scientific societies for the diagnosis of the metabolic syndrome

\begin{tabular}{|c|c|c|c|}
\hline Organization & $\begin{array}{l}\text { AHA/NHLBI/updated } \\
\text { NCEP-ATPIII, }{ }^{3} 2005\end{array}$ & IDF $^{4}(2005)$ & $\mathrm{JIS}^{5}(2009)$ \\
\hline Required criteria & $\geq 3$ of the following & $\begin{array}{l}\text { Central obesity (defined by waist } \\
\text { circumference according to ethnicity) plus } \\
\geq 2 \text { of the following }\end{array}$ & $\geq 3$ of the following \\
\hline Fasting blood glucose & $\geq 100 \mathrm{mg} / \mathrm{dL}$ & $\geq 100 \mathrm{mg} / \mathrm{dL}$ & $\geq 100 \mathrm{mg} / \mathrm{dL}$ \\
\hline HDL cholesterol & $\begin{array}{l}<40 \mathrm{mg} / \mathrm{dL}\left({ }^{\Uparrow}\right) \\
<50 \mathrm{mg} / \mathrm{dL}(+)\end{array}$ & $\begin{array}{l}<40 \mathrm{mg} / \mathrm{dL}\left({ }^{\Uparrow}\right) \\
<50 \mathrm{mg} / \mathrm{dL}(+)\end{array}$ & $\begin{array}{l}<40 \mathrm{mg} / \mathrm{dL}(ð) \\
<50 \mathrm{mg} / \mathrm{dL}(+)\end{array}$ \\
\hline Triglycerides & $\geq 150 \mathrm{mg} / \mathrm{dL}$ & $\geq 150 \mathrm{mg} / \mathrm{dL}$ & $\geq 150 \mathrm{mg} / \mathrm{dL}$ \\
\hline Waist circumference & $\begin{array}{l}\geq 102 \mathrm{~cm}\left({ }^{7}\right) \\
\geq 88 \mathrm{~cm}(+)\end{array}$ & 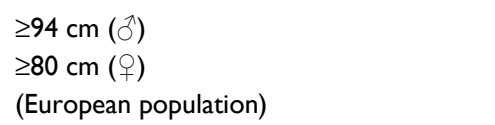 & $\begin{array}{l}\geq 94 \mathrm{~cm}\left({ }^{\Uparrow}\right) \\
\geq 80 \mathrm{~cm}(+) \\
\text { (Mediterranean population) }\end{array}$ \\
\hline Hypertension & $\begin{array}{l}\geq 130 / 85 \mathrm{mmHg} \\
\text { or being treated }\end{array}$ & $\begin{array}{l}\geq 130 / 85 \mathrm{mmHg} \\
\text { or being treated }\end{array}$ & $\begin{array}{l}\geq 130 / 85 \mathrm{mmHg} \\
\text { or being treated }\end{array}$ \\
\hline
\end{tabular}

Abbreviations: AHA/NHLBI/NCEP-ATPIII, American Heart Association/National Heart, Lung, and Blood Institute/National Cholesterol Education Program-Adult Treatment Panel III; IDF, International Diabetes Federation; JIS, Joint Interim Statement of the International Diabetes Federation Task Force on Epidemiology and Prevention; National Heart, Lung, and Blood Institute; American Heart Association; World Heart Federation; International Atherosclerosis Society, and International Association for the Study of Obesity; HDL, high-density lipoproteins.

chronic inflammation, an increase in ultrasensitive C-reactive protein and cytokines, oxidative stress, hypercoagulable state with increased inhibitor of plasminogen activator type 1 (PAI-1), and hyperfibrinogenemia have also been described. ${ }^{1-5}$

MetS is considered clinically significant owing to its high prevalence $(0 \%-40 \%$ of the general population and $80 \%-$ $85 \%$ of patients with T2DM), its possible complications, and its potential reversibility and treatability. Complications are progressive and cumulative and associated with the degree of patient obesity and disease duration. ${ }^{6}$

MetS identifies patients with a high risk of T2DM and CVD as well as numerous other complications. A recent meta-analysis indicated that those with MetS have a twofold increased risk of cardiovascular (CV) events and a 1.5-fold increased risk of death from all causes. ${ }^{7}$ Numerous studies analyzed the relationship between the MetS and T2DM. In a substudy of the Framingham Offspring Study, a relative risk of T2DM was increased by the number of the MetS components. ${ }^{8}$ A meta-analysis with 42,419 participants from 16 cohorts found the relative risk of an incidence of T2DM to be 3.5-5.2 times higher, with no significant differences in the definition of the MetS used. ${ }^{9}$ More recent studies point to a relative risk of between 5 and 10 times for the development of T2DM. ${ }^{10}$ Finally, the association of obesity and cancer is increasingly significant: a higher incidence of breast, uterus, colon, esophageal, pancreatic, kidney, and prostate cancers has been found in obese patients. ${ }^{11}$ The possible complications associated with MetS, insulin resistance (IR), and abdominal obesity are shown in Figure 1.

\section{Vascular risk in MetS}

Several studies confirmed that patients with MetS have an increased risk of vascular complications such as coronary heart disease, stroke, and peripheral arterial disease. ${ }^{7,12}$ In general, an increase in risk barely differs according to the criteria used to define MetS, and CV risk is as high as the number of MetS components. ${ }^{7}$ For example, in a study carried out by Klein et al, ${ }^{13}$ the risk of 5-year CVD varied from $2.5 \%$ in patients with a single MetS component to $14.9 \%$ in those with four or more.

However, doubts remain as to whether the risk attributable to this syndrome is greater than the sum of its parts. The relative risk of death and CV complications attributable to MetS was reviewed in a meta-analysis that analyzed 87 studies with 951,083 participants and showed its association with a twofold increase in CV results (Table 2). ${ }^{7}$ Furthermore, the relative risk in females was significantly higher than that in males. When patients with T2DM were excluded from the analysis, the relative risk of $\mathrm{CV}$ events and deaths attributable to MetS was reduced but remained significant (Table 3).

The increase in risk attributable to MetS has not only been observed in patients without diabetes in primary prevention but also in patients with coronary heart disease and those with T2DM.

\section{Vascular risk in patients with established vascular disease and MetS}

Data on the impact of MetS on the risk of new events developing in patients with established CVD are slightly discordant. 


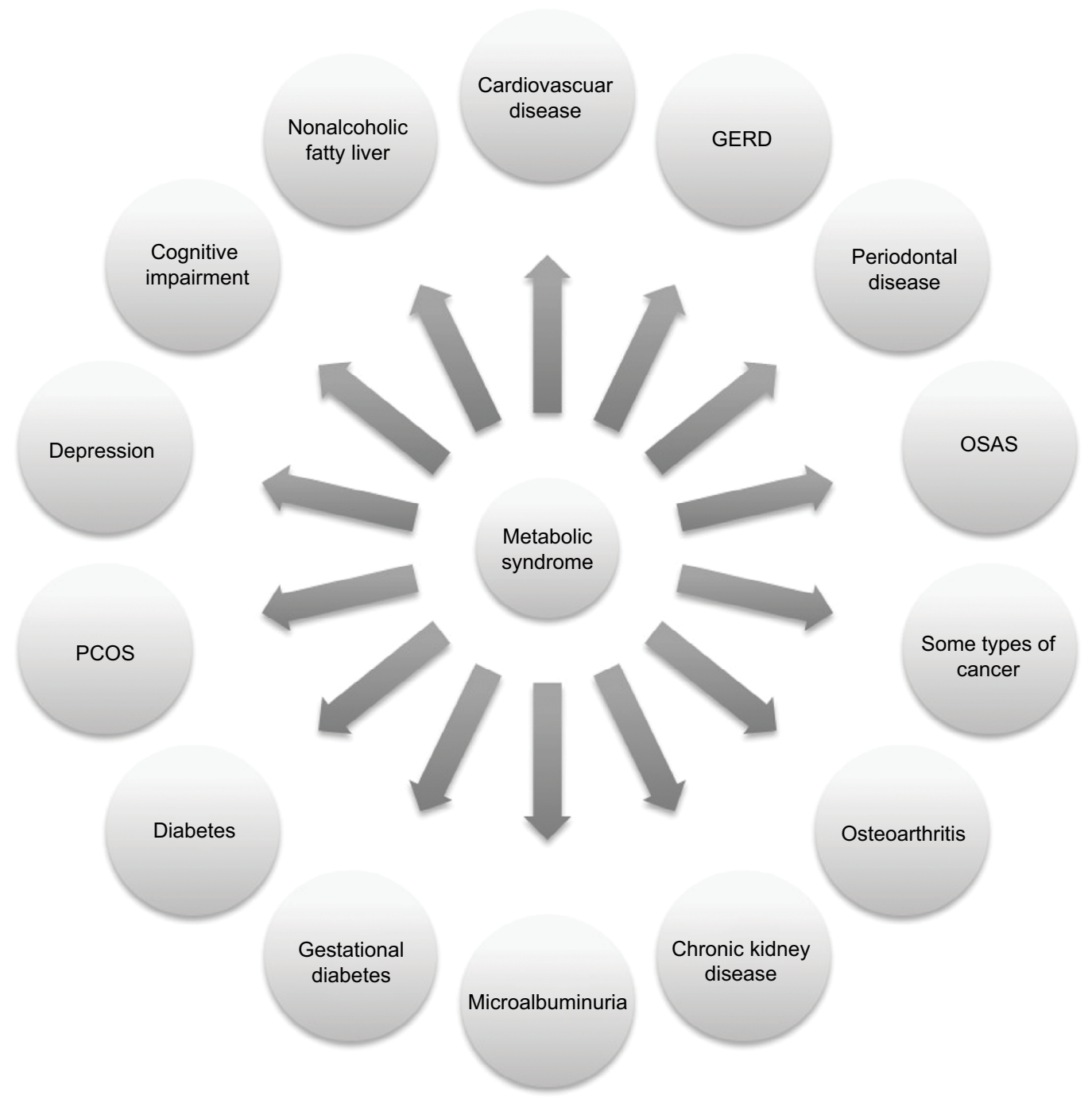

Figure I Main comorbidities associated with the metabolic syndrome.

Abbreviations: GERD, gastro-esophageal reflux disease; PCOS, polycystic ovary syndrome; OSAS, obstructive sleep apnea syndrome.

Table 2 Relative risk of cardiovascular events and death in patients with metabolic syndrome*

\begin{tabular}{llll}
\hline Outcomes & \multicolumn{2}{l}{ Relative risk $(95 \% \mathrm{Cl})$} \\
\cline { 2 - 4 } & Total & Male & Female \\
\hline Total mortality & $\mathrm{I} .58(\mathrm{I} .39-\mathrm{I} .78)$ & $\mathrm{I} .42(\mathrm{I} .16-\mathrm{I} .74)$ & $\mathrm{I} .86(\mathrm{I} .37-2.52)$ \\
CV mortality & $2.40(\mathrm{I} .87-3.08)$ & $\mathrm{I} .94(\mathrm{I} .20-3.14)$ & $2.55(\mathrm{I} .4 \mathrm{I}-4.60)$ \\
CV disease & $2.35(2.02-2.73)$ & $2.14(\mathrm{I} .62-2.83)$ & $2.87(2.40-3.43)$ \\
Myocardial & $\mathrm{I} .99(\mathrm{I} .6 \mathrm{I}-2.46)$ & $2.0 \mathrm{I}(\mathrm{I} .52-2.67)$ & $2.57(0.87-7.57)$ \\
infarction & & & \\
Stroke & $2.27(\mathrm{I} .80-2.85)$ & $2.00(\mathrm{I} .38-2.88)$ & $2.59(\mathrm{I} .94-3.46)$ \\
\hline
\end{tabular}

Note: *When compared with patients without metabolic syndrome. Abbreviation: CV, cardiovascular.

Although, in most studies, MetS increased the risk to the same level as that observed in patients without CVD, ${ }^{14,15}$ in other studies, the effect of MetS in patients with CVD appeared to be lower. ${ }^{16}$ In general, the relative risk of severe $\mathrm{CV}$ events associated with the presence of MetS in this population varied between 1.4 and 1.5 after patients with T2DM were excluded.
Table 3 Relative risk of cardiovascular events and death in nondiabetic patients with metabolic syndrome*

\begin{tabular}{ll}
\hline Outcomes & Relative risk $(95 \% \mathbf{~ C l})$ \\
\hline Total mortality & $1.32(0.65-2.67)$ \\
CV mortality & $1.75(1.19-2.58)$ \\
Myocardial infarction & $1.62(1.31-2.01)$ \\
Stroke & $1.86(1.10-3.17)$ \\
\hline
\end{tabular}

Note: *When compared with patients without metabolic syndrome. Abbreviation: $\mathrm{CV}$, cardiovascular.

\section{Vascular risk in patients with diabetes and MetS}

Few studies analyzed the additional risk attributable to the MetS in patients with T2DM. In the FIELD study, ${ }^{16}$ conducted exclusively in patients with T2DM, MetS was accompanied by an increased risk of CV events. This effect was greater for participants who did not have CVD at the start of the study than for those who did. The higher the number of MetS 
criteria, the higher the risk. In the Strong Heart Study with patients who did not have CVD,${ }^{17}$ the risk of fatal or nonfatal $\mathrm{CV}$ complications was higher in patients with MetS whether or not they had diabetes at the start of follow-up. Having MetS implies an increased risk of CV complications and death. This is valid in patients in primary prevention with and without T2DM and in those with established CVD.

However, the diagnosis of MetS implicitly carries, in a significant number of cases, a diagnosis of hypertension, a risk factor already included in the risk estimation charts. Therefore, including MetS in the estimation of risk by directly multiplying the risk emerging from a risk equation by the relative risk attributable to the MetS would imply magnifying this risk, as hypertension has been considered twice. This is, at least in part, the reason why no consensus exists as to how the MetS should modulate the risk emerging from $\mathrm{CV}$ risk equations. In this regard, the latest 2016 European guidelines on $\mathrm{CV}$ prevention do not refer to the MetS but state that obesity, particularly central obesity, could play a modulating role in risk. ${ }^{18}$ Meanwhile, when addressing the debate regarding the increase in $\mathrm{CV}$ risk in the population with the MetS, the European Society of Cardiology (ESC) and European Atherosclerosis Society (EAS) guideline for the control of dyslipidemia suggests that the combination of increased waist circumference and elevated triglycerides is a simple and inexpensive screening tool to filter patients with MetS who have a high CV risk. ${ }^{19}$

\section{Abdominal obesity}

Obesity and MetS are two closely related complex entities whose growing prevalence in the population has become a serious public health problem in Western countries. From a clinical perspective, the difficulty lies in identifying the effect attributable to each entity when estimating the risk of developing CVD or T2DM. However, control of these metabolic alterations also directly affects the morbidity and mortality of other chronic diseases (Figure 1), which obligates to establishing effective preventive, diagnostic, and therapeutic strategies. Although both processes do present together, it is well established that they are not necessarily associated. The presence of abdominal obesity has a negative impact on the different components of MetS such as blood pressure, waist circumference, plasma glucose levels, HDL cholesterol, and triglycerides. ${ }^{20}$ It is important to emphasize that the most accepted and constant diagnostic parameter for MetS is central obesity, calculated using body mass index (BMI) and waist circumference, with the latter being a variable depending on the ethnicity and sex of the patient being analyzed. In our milieu, we consider abdominal obesity to be waist circumference, measured just above the iliac crests, $\geq 94 \mathrm{~cm}$ in Caucasian males or $\geq 80 \mathrm{~cm}$ in Caucasian females. ${ }^{1}$ Its importance is based on the fact that central obesity is one of the most significant triggers of other metabolic alterations in the pathogenesis of the MetS, including IR. This explains the presence of MetS in obese patients, in most cases, and that it is largely a comorbidity of obesity. Finally, it is important to point out that the use of uniform definitions of obesity and MetS is crucial for the detection of both conditions in routine clinical practice. ${ }^{21}$

When considering the diagnosis of these processes, their progressive nature should be noted and that they include different clinical stages. Initially, they debut with the presence of causative factors (central adiposity and IR, together with the genetic component that characterizes each patient) and subsequently lead to the aforementioned metabolic alterations (hypertension, dyslipidemia, and alteration of hydrocarbon metabolism). Next, vasculopathy develops in an initial subclinical stage, and atherothrombotic complications and the development of T2DM finally appear. For this reason, we should not only limit diagnosis to the presence of metabolic alterations but also consider the possibility of preestablished subclinical alterations.

Since suitable lifestyle changes significantly reduce the risk factors associated with MetS, management of both the processes should include recommendations for a healthy lifestyle, emphasizing physical activity, a healthy eating plan, and smoking and alcohol avoidance. In this respect, a group of international experts recently defined a set of lifestyle recommendations for the prevention and treatment of MetS, including aspects regarding weight control. ${ }^{22}$

\section{Hyperglycemia/diabetes}

Since most of the patients with MetS have IR, an overlap between the prevalence of hyperglycemia and the MetS is not surprising. The latter has traditionally been considered a prediabetic state; compared to patients without MetS, those with MetS have fourfold greater risk of T2DM. ${ }^{23}$

In the evolution of MetS and as a consequence of IR, compensating hyperinsulinism appears which can temporarily maintain glucose metabolism within the normal range. Subsequently, alteration in glucose metabolism (prediabetes or diabetes) appears because of a deficit, at least relative, of insulin secretion. Several methods have been developed to assess peripheral insulin sensitivity. Of the in vivo methods, the hyperinsulinemic euglycemic clamp stands out and is considered the gold standard. In clinical practice, indirect formulae 
such as the homeostatic model assessment-insulin resistance (HOMA-IR) index are used. In our experience, based on a Valencian and Spanish population, we defined IR as baseline or fasting plasma insulin $\geq 14 \mathrm{mU} / \mathrm{L}$ or $\mathrm{HOMA}_{\mathrm{IR}}$ [insulin $\mathrm{mU} / \mathrm{L}$ $\times$ glucose $\mathrm{mmol} / \mathrm{L} / 22.5]) \geq 3.2$. Clinically, abdominal obesity and hypertriglyceridemia indicate a high probability of IR that rises if blood glucose levels are altered. ${ }^{24}$

\section{Increased risk categories for diabetes}

These are fundamentally impaired glucose tolerance (IGT) and impaired fasting blood glucose (IFG). The first is considered when plasma glucose ranges from $140 \mathrm{mg} / \mathrm{dL}$ to $199 \mathrm{mg} / \mathrm{dL}$ at 2 hours of an oral glucose tolerance test (OGTT) ( $75 \mathrm{~g}$ ) and IFG from $100 \mathrm{mg} / \mathrm{dL}$ to $125 \mathrm{mg} / \mathrm{dL}$ in fasting. Also, diabetes is understood to exist when fasting blood glucose values are $\geq 126 \mathrm{mg} / \mathrm{dL}$ or $\geq 200 \mathrm{mg} / \mathrm{dL}$ at 2 hours of OGTT. ${ }^{25}$

Recently, plasma glycosylated hemoglobin $\left(\mathrm{HbA}_{1 \mathrm{c}}\right)$ levels have been begun to be used for the diagnosis of prediabetes and diabetes. Levels between 5.7\% and 6.4\% are considered diagnostic of prediabetes, whereas levels $\geq 6.5 \%$ are considered diagnostic of diabetes. ${ }^{25}$

The development of T2DM is associated with an increased CV risk of 2-4 times higher than the rate observed in the population of similar age and sex without diabetes, ${ }^{26,27}$ which is considered a situation of high CV risk. Recently, the American Association of Clinical Endocrinologists and the American College of Endocrinology (AACE-ACE) considered T2DM to be a high $\mathrm{CV}$ risk. ${ }^{28} \mathrm{~T} 2 \mathrm{DM}$ associated with a risk factor (either high LDL cholesterol, smoking, hypertension, HDL cholesterol $<40 \mathrm{mg} / \mathrm{dL}$, family history of CVD in first-degree male relatives aged $<55$ years or female relatives aged $<65$ years, stage $3 / 4$ chronic kidney disease, coronary calcification, and males aged $\geq 45$ years or females aged $\geq 55$ years) is considered a very high CV risk. Finally, the category of extreme $\mathrm{CV}$ risk is established in patients with T2DM and clinically established CVD, in which a target LDL cholesterol $<55 \mathrm{mg} / \mathrm{dL}$ is recommended.

\section{Treatment of hyperglycemia and diabetes}

An improvement in glycemic control yielded no significant impact on CVD prevention, possibly due to the study designs or because desirable $\mathrm{HbA}_{\mathrm{lc}}$ levels were not reached and maintained long enough and with drugs without the hypoglycemic risk, although a reduction in the number of $\mathrm{CV}$ events was observed. ${ }^{27}$

Lifestyle modification is essential for correct control of hyperglycemia and IR, and consequently all components of MetS. In the short-medium term, adherence to a low glycemic load/high fiber-content diet is sufficient for the control of hyperglycemia. ${ }^{29} \mathrm{~A}$ Mediterranean diet relatively rich in vegetable fats has also been confirmed as effective. There is evidence that a loss of $7 \%$ of initial body weight following a healthy diet and carrying out moderate physical activity (such as brisk walking) of at least 150 minutes/week can prevent the development of diabetes in predisposed individuals. ${ }^{30}$

The pharmacological treatment of T2DM includes the use of oral antidiabetics in monotherapy or in combination with noninsulin injectable drugs and insulin. Insulin-sensitizing antidiabetics such as metformin and glitazones (pioglitazone) reduce IR, improve metabolic control, hypertension, dyslipidemia, and other components of MetS, and are essential in the treatment of T2DM with MetS.

Similarly, antidiabetics that lower the patients' weight such as glucagon-like peptide-1 (GLP-1) receptor agonists and SGLT-2 inhibitors play an important role. Some antidiabetics have recently been shown to reduce $\mathrm{CV}$ events in patients with T2DM and established CVD (empagliflozin, liraglutide, and canagliflozin). ${ }^{31-33}$

In the treatment of MetS, some antidiabetics may play a protective role in preventing progression to T2DM. In patients with prediabetes (MetS), metformin has been shown to assist in the prevention of diabetes by $25 \%-30 \%{ }^{30}$ and pioglitazone by $72 \% .{ }^{34}$ Conversely, pioglitazone has also been shown to be effective in diabetes prevention in patients with fatty liver and for the control of fatty acid supply to the liver. ${ }^{35}$

GLP-1 receptor agonists reduce prediabetes or conversion to T2DM. Currently, although not funded by the public health system, a high-dose liraglutide ( $3 \mathrm{mg}$ ) formula has become available, which the SCALE program has found to be effective for weight loss and in reducing the risk of progression from prediabetes to diabetes..$^{36,37}$

Since no data are available on the goal of glycemic control in patients with MetS without T2DM, the routine use of an antidiabetic drug is not recommended. However, preventive treatment with metformin can be considered in patients with IGT, IFG, or $\mathrm{HbA}_{1 \mathrm{c}}$ level of $5.7 \%-6.4 \%$, particularly if they have a BMI $>35 \mathrm{~kg} / \mathrm{m}^{2}$, are under 60 years, and are females with previous gestational diabetes. ${ }^{38}$

An alternative to pharmacological treatment is bariatric surgery, when BMI $>40 \mathrm{~kg} / \mathrm{m}^{2}$ or $>35 \mathrm{~kg} / \mathrm{m}^{2}$ plus comorbidities are associated with excess weight.

\section{Arterial hypertension}

No changes to the blood pressure criteria for MetS have been suggested by either the National Cholesterol Education Program-Adult Treatment Panel III (NCEP-ATPIII) ${ }^{2}$ 
or the International Diabetes Federation ${ }^{4}$ and following the consolidations of the American Heart Association/ National Heart, Lung, and Blood Institute Document (AHA/ NHLBI). ${ }^{3}$ Most clinical guidelines for the diagnosis and treatment of hypertension do not currently consider MetS as a modifier of therapeutic recommendations. ${ }^{39-41}$ In general, the criteria for starting pharmacological treatment are established at 140/90 mmHg. Specific interventions for individuals with lower levels have not been described beyond general population recommendations to reduce salt intake, maintain an adequate weight, and practice physical exercise.

In hypertensive individuals, reducing to levels below $140 / 90 \mathrm{mmHg}$ is recommended. ${ }^{39-41}$ Values $<150 \mathrm{mmHg}$ are considered acceptable in patients aged $>80$ years or in those aged $>60$ years and are very fragile and/or at risk of falls due to orthostatic hypotension. ${ }^{39-41}$ The ESC CV prevention guideline also recommends $\mathrm{SBP}<140 \mathrm{mmHg}$ for all hypertensive patients aged $<60$ years. ${ }^{19}$ In patients aged $>60$ years with SBP >160 mmHg, lowering their SBP to 140-150 mmHg is recommended. ${ }^{19}$

In hypertensive individuals with diabetes, a reduction in SBP to $<140 \mathrm{mmHg}$ is suggested. ${ }^{39-41}$ Recommendations for DBP levels are not the same in all guidelines but are mostly $<90 \mathrm{mmHg}{ }^{40,41}$ The 2013 European guideline suggests reducing it to $<85 \mathrm{mmHg} .{ }^{39}$

Recently, the SPRINT study showed the benefits of a reduction in SBP to $<120 \mathrm{mmHg}$. ${ }^{42}$ However, since the methods used for measuring blood pressure were not like those normally used in clinical practice, the results could not be easily generalized and, in any event, would have corresponded to values close to $130 \mathrm{mmHg}$ if conventionally measured. The patients in that study were hypertensive without diabetes but had a high CV risk. The proportion of patients with MetS was unknown, and a subgroup analysis was not specified in those patients.

In November 2017, the American College of Cardiology, AHA, and related societies' guideline modified the diagnostic criteria for hypertension, establishing them at levels $>130$ and/or $80 \mathrm{mmHg}$ and recommended modifications in all patients' lifestyles based on these figures, in addition to antihypertensive pharmacological treatment for levels $\geq 140$ and/or $90 \mathrm{mmHg}$ or levels $\geq 130$ and/or $80 \mathrm{mmHg}$ if 10 -year CV risk is $>10 \%$ according to the risk chart equation. ${ }^{43}$ This risk estimate considers MetS components such as diabetes and HDL cholesterol. On this basis, many patients with MetS and blood pressure levels $\geq 130$ and/or $80 \mathrm{mmHg}$ would be candidates for pharmacological therapy.

\section{Treatment}

No comparative studies have been conducted among antihypertensive drugs that have included CV morbidity and mortality objectives in patients with MetS. Indirect evidence suggests that drugs that inhibit the renin angiotensin system (angiotensin converting enzyme inhibitors [ACEI] and angiotensin II receptor blockers [ARB-2]) and calcium channel blockers have neutral effects on IR and are equally neutral or slightly positive on the onset of diabetes. ${ }^{44}$ Other first-line pharmacological groups such as thiazide diuretics and beta-blockers increase IR and the risk of developing de novo T2DM.

\section{Dyslipidemia of MetS Pathogenic bases}

MetS favors the development of atherosclerosis, and its characteristic dyslipidemia contributes to it significantly. It comprises two lipid alterations that contribute to its diagnostic criteria: fasting triglyceridemia $>150 \mathrm{mg} / \mathrm{dL}$ and an $\mathrm{HDL}$ cholesterol concentration $<40 \mathrm{mg} / \mathrm{dL}$ in males and $<50 \mathrm{mg} /$ $\mathrm{dL}$ in females. Its base is increased synthesis of very lowdensity lipoproteins (VLDL), since liver is overexposed to an excess of free fatty acids from adipose tissue, a reduction in the lipolytic capacity of plasma and an increase in the activity of cholesterol ester transfer protein, which involves reducing the cholesterol content of HDL. ${ }^{17,45}$

Low HDL cholesterol is a recognized independent risk factor. ${ }^{46}$ The protective action of HDL has been associated with its ability to remove cholesterol from peripheral tissues and its antioxidant effect that prevents the oxidation of LDL in the subendothelial space. Although this association is close, Mendelian randomization and pharmacological intervention studies have not shown a clinical benefit in the increase in HDL cholesterol. ${ }^{47}$ The REVEAL study recently showed that adding anacetrapib (100 $\mathrm{mg} /$ day) to intensive statin therapy for $\sim 4$ years results in a lower incidence of severe coronary events compared to adding placebo in patients with CVD and baseline levels of controlled LDL cholesterol (mean, $61 \mathrm{mg}$ / $\mathrm{dL}[1.58 \mathrm{mmol} / \mathrm{L}]) .{ }^{48} \mathrm{~A} 9 \%$ reduction in $\mathrm{CV}$ events cannot be explained by the doubling of HDL cholesterol levels alone, and the reduction in non-HDL cholesterol seemed to be the main cause of the observed effect of anacetrapib.

By contrast, although the association between hypertriglyceridemia and $\mathrm{CV}$ risk is weakened when adjusted for other factors, recent Mendelian randomization studies indicate that triglyceride-rich lipoproteins play a key role in the predisposition to atherosclerosis. Triglycerides do not accumulate like cholesterol in atheromatous plaque and are 
thus indirectly atherogenic, either through the lowering of HDL cholesterol or by the accumulation of lipoproteins with direct atherogenic capacity. First, there is an increase in LDL particles enriched in triglycerides and depleted in cholesterol which, in addition to changing their density, makes them smaller, giving them greater ability to infiltrate the arterial wall, become trapped by proteoglycans in the subendothelial space, and oxidize. Second, hypertriglyceridemia leads to the accumulation of VLDL and chylomicron remnant particles which, because of their size, cross into the subendothelial space and contribute, like LDL, to atheromatous plaque. Third, an overproduction of VLDL increases competition with chylomicrons for lipoprotein lipase such that the latter can accumulate during fasting. ${ }^{49}$

Since all apoB-containing particles are atherogenic, quantifying this apoprotein as an expression of VLDL, IDL, and LDL has been suggested. In its absence, the quantification of non-HDL cholesterol concentration provides the clinician with a useful tool for measuring all atherogenic cholesterol. ${ }^{50}$

In recent years, lipoprotein(a) [Lp(a)] as a CV risk factor has been revisited, mainly in patients with familial hypercholesterolaemia. ${ }^{51}$ For unknown reasons, hypertriglyceridemia and other components of the MetS, particularly those related to IR, showed an inverse association with $\mathrm{Lp}(\mathrm{a})$ concentrations. ${ }^{52}$ Furthermore, Lp(a) levels in patients with coronary heart disease were predictors of CVD only in patients without MetS. ${ }^{53}$

Proprotein convertase subtilisin/kexin type 9 (PCSK9) is a protein that regulates the expression of LDL receptors and, consequently, circulates LDL cholesterol levels. ${ }^{54}$ PCSK9 concentrations in the MetS and atherogenic dyslipidemia are high compared with patients without MetS. ${ }^{55,56}$ In addition, change from a typical American diet to a Mediterranean diet in patients with MetS results in a drop in PCSK9 concentration and a consequent reduction in LDL cholesterol. ${ }^{57}$

All these data taken together suggest that dyslipidemia associated with MetS contributes to increased CV risk.

\section{Dyslipidemia}

Atherogenic dyslipidemia, typical of the MetS, includes an increase in triglycerides and remnant particles in both postprandial and fasting states, a deficit of HDL cholesterol and apoA 1 and an excess of apoB associated with predominance of small and dense LDL particles. This dyslipidemia is also characteristic of T2DM and abdominal obesity. Among all the lipid alterations of atherogenic dyslipidemia, the excess of apoB-containing lipoproteins is the most remarkable owing to its atherogenic potential. The sum of the cholesterol contained in these lipoproteins corresponds to non-HDL cholesterol and is calculated simply by subtracting HDL cholesterol from total cholesterol. The reference levels of non-HDL cholesterol are those obtained by adding $0.8 \mathrm{mmol} / \mathrm{L}(30 \mathrm{mg} / \mathrm{dL})$ to the reference values of LDL cholesterol. We have seen in patients with MetS that nonHDL cholesterol is a better predictor of CV risk than LDL cholesterol. This is due to the fact that Friedewald's formula loses precision in the calculation of LDL cholesterol when there is hypertriglyceridemia, given that non-HDL cholesterol includes all apoB lipoproteins which are atherogenic. NonHDL cholesterol has a strong correlation with serum apoB concentration. ${ }^{58}$ In some studies, apoB, which is equivalent to the total number of atherogenic lipoprotein particles, correlated more strongly with $\mathrm{CV}$ risk and was a better predictor of the protective effect of statins against CVD and of achieving therapeutic targets than LDL cholesterol or non-HDL cholesterol, but not in all of them. ${ }^{59,60}$ Laboratory methods for measuring apoB are standardized, but are not available in all clinical laboratories and imply an additional cost; thus, non-HDL cholesterol is most often used in clinical practice. Discrepancies among apoB, LDL cholesterol, and non-HDL cholesterol are greater in patients with MetS. ${ }^{61}$ Similarly, a reduction in LDL and non-HDL cholesterol obtained with statins is proportionally greater than a decrease in apoB. Therefore, it is more difficult to reach apoB targets than those of LDL cholesterol or non-HDL cholesterol. ${ }^{62}$

On the other hand, large clinical intervention studies have shown that lower the atherogenic cholesterol is, the greater the preventive effect will be against $\mathrm{CVD},{ }^{63}$ which is consistent with the fact that the harmful effect of atherogenic cholesterol on the arterial wall is greater in patients with MetS or IR than in individuals without such disorders. ${ }^{64}$

In patients with atherogenic dyslipidemia, the main therapeutic goal is to reduce non-HDL cholesterol, although if there is no excess of triglycerides $(<200 \mathrm{mg} / \mathrm{dL}), \mathrm{LDL}$ cholesterol can also be considered. The first-choice drugs to achieve this goal are statins. They lower CV risk by 23\% per $\mathrm{mmol} / \mathrm{L}(\sim 40 \mathrm{mg} / \mathrm{dL})$ of LDL cholesterol decrease, regardless of baseline concentrations or other patient characteristics. ${ }^{65}$ Thus, the reduction in relative risk obtained by treating with statins is similar in patients with and without MetS or T2DM. However, if we also consider that the absolute CV risk of patients with T2DM or MetS is higher, then the absolute benefit of the treatment - that is, the number of cases of CVD avoided - is also greater, and thus fewer patients will be treated and the economic cost that has to be allocated to avoiding $\mathrm{CV}$ events will be lower. 
Strong evidence from meta-analyses and other clinical studies using high doses of statins shows that a reduction in LDL cholesterol - even in individuals with normal or low LDL cholesterol - reduces mortality, in both primary and secondary prevention settings, and that patients with MetS benefit more from the use of statins than those without, perhaps because their $\mathrm{CV}$ risk is higher. ${ }^{66,67}$

Non-HDL and LDL cholesterol and apoB targets for patients with high or very high CV risk according to the 2016 ESC/EAS guideline ${ }^{19}$ and the National Lipid Association ${ }^{68}$ are shown in Table 4. A wide evidence is provided by clinical trials in patients with MetS to justify these objectives. ${ }^{16,69,70}$ As mentioned, statins lower non-HDL cholesterol to a greater extent than apoB, and a more aggressive treatment is needed to achieve apoB targets than to reach non-HDL cholesterol targets. ${ }^{71-73}$

Dietary measures and lifestyle improvements are essential for all patients with MetS to prevent both CVD and T2DM. ${ }^{74}$

The first-choice pharmacological treatment to achieve non-HDL cholesterol targets in patients with MetS is moderate to high intensity statins. Among the former, which lowers LDL cholesterol by between $30 \%$ and $50 \%$, are atorvastatin at a dose of $10-40 \mathrm{mg} /$ day, rosuvastatin $5-10 \mathrm{mg} /$ day, simvastatin $20-40 \mathrm{mg}$ /day, pitavastatin $2-4$ $\mathrm{mg} /$ day, pravastatin $40 \mathrm{mg} /$ day, and fluvastatin $80 \mathrm{mg} /$ day. High-intensity statins, which lower LDL cholesterol by at least $50 \%$, include atorvastatin at a dose of $80 \mathrm{mg} /$ day or rosuvastatin at $20-40 \mathrm{mg} /$ day. ${ }^{75}$ If the LDL or non-HDL cholesterol target is not achieved with a statin in monotherapy at the maximum tolerated dose, ezetimibe can be combined, providing an additional $20 \%-25 \%$ reduction. In this respect, the hypocholesterolemic efficacy of a statin-ezetimibe association has been observed to be the same in patients with and without MetS. ${ }^{76}$

Another aspect to consider when selecting a statin is the risk of intolerance or side effects that is somewhat greater in MetS patients. ${ }^{77}$ Since these patients are usually being treated with multiple drugs, statins that have lower potential

Table 4 Primary objectives of treatment of atherogenic dyslipidemia in patients with metabolic syndrome

\begin{tabular}{|c|c|c|c|}
\hline $\begin{array}{l}\text { Cardiovascular } \\
\text { risk }\end{array}$ & $\begin{array}{l}\text { LDL } \\
\text { cholesterol }\end{array}$ & $\begin{array}{l}\text { Non-HDL } \\
\text { cholesterol }\end{array}$ & ApoB \\
\hline High CVR & $\begin{array}{l}<100 \mathrm{mg} / \mathrm{dL} \\
(2.6 \mathrm{mmol} / \mathrm{L})\end{array}$ & $\begin{array}{l}<130 \mathrm{mg} / \mathrm{dL} \\
(3.4 \mathrm{mmol} / \mathrm{L})\end{array}$ & $<100 \mathrm{mg} / \mathrm{dL}$ \\
\hline Very high CVR & $\begin{array}{l}<70 \mathrm{mg} / \mathrm{dL} \\
(1.8 \mathrm{mmol} / \mathrm{L})\end{array}$ & $\begin{array}{l}<100 \mathrm{mg} / \mathrm{dL} \\
(2.6 \mathrm{mmol} / \mathrm{L})\end{array}$ & $<80 \mathrm{mg} / \mathrm{dL}$ \\
\hline
\end{tabular}

Abbreviations: CVR, cardiovascular risk; LDL, low-density lipoproteins; HDL, high-density lipoproteins; Apo, apolipoprotein. for drug interactions such as rosuvastatin and pitavastatin should be used. Another aspect to consider is the potential of statins to alter glucose metabolism, an effect which, although small, is more significant in patients with MetS, since this population has a higher risk of developing T2DM. Unlike other statins, pitavastatin has been shown to lack a diabetogenic effect, ${ }^{78}$ a characteristic that Spanish primary and specialized healthcare professionals are already well aware of and which was discussed in a recent consensus document on the treatment of dyslipidemia in patients with impaired glucose metabolism. ${ }^{79,80}$

An anti-PCSK9 monoclonal antibody, that is, alirocumab or evolocumab, can be used for patients with MetS who do not reach non-HDL cholesterol targets with prior lipid-lowering drugs. However, the use of these new drugs is restricted for the time being to patients in secondary prevention and those with familial hypercholesterolemia whose LDL cholesterol falls outside targets despite treatment with statins at maximum tolerated doses. ${ }^{81}$

Fibrates have been used with good results in primary and secondary prevention in situations characterized by increased triglycerides with or without low HDL cholesterol, which is very common in patients with T2DM and MetS. Consequently, clinical guidelines such as the International Atherosclerosis Society 2014, ${ }^{60}$ EAS/ESC $2016,{ }^{19}$ Sociedad Española de Arteriosclerosis (SEA) 2017, ${ }^{82}$ and AACE-ACE $2017^{28}$ recommend the use of fibrates in patients at high/very high $\mathrm{CV}$ risk when there is an increase in triglycerides, nonHDL cholesterol, or atherogenic dyslipidemia, once LDL cholesterol has been controlled. A recent Cochrane review in primary prevention showed that the benefit emerges from the reduction in a combined objective of $\mathrm{CV}$ mortality, nonfatal infarction, and nonfatal stroke $(-16 \%)$, or a combination of coronary mortality and nonfatal infarction $(-21 \%)$, with no significant changes in non-CV mortality or any cause. ${ }^{83}$ In another Cochrane review on secondary prevention, ${ }^{84}$ the benefit arises from the reduction in a combined objective of CV mortality, infarction (fatal and nonfatal), and stroke (fatal and nonfatal) $(-12 \%)$ as well as a significant reduction in myocardial infarction (fatal and nonfatal) $(-14 \%)$. The maximum benefit of fibrate therapy is found when atherogenic dyslipidemia is present; in this specific group, the relative CVD risk is reduced by up to $35 \%$.

\section{MetS: a prothrombotic state}

Patients with MetS have hemostatic alterations that can raise both atherothrombotic and thromboembolic $\mathrm{CV}$ risk. ${ }^{85}$ Both are caused by a reduction in vasodilator agent activity and an 
increase in the expression of vasoconstrictors as a consequence of endothelial dysfunction. This dysfunction is the result of chronic inflammation, dyslipidemia, and hypertension. There is also a hypercoagulability state related to impaired liver production of coagulation factors and proinflammatory cytokines as a consequence of IR. ${ }^{86}$ This hypercoagulability is accompanied by impaired fibrinolysis and platelet dysfunction, ${ }^{87,88}$ a result of high levels of PAI- $1,{ }^{87,89}$ tissue factor, ${ }^{90,91}$ fibrinogen, ${ }^{89}$ and factor VIII activity. ${ }^{92}$ Jointly, evidence exists of the effect of several adipokines, such as leptin and adiponectin, on platelet function, ${ }^{93}$ with increased baseline platelet reactivity, lower antiplatelet response to aspirin, ${ }^{92}$ and increased risk of venous thrombosis being described in MetS. ${ }^{94}$

From a therapeutic perspective, caloric restriction and weight loss are accompanied by a reduction in the activation of coagulation factors. ${ }^{95}$ Specific pharmacological therapies other than aspirin to treat the prothrombotic state of patients with MetS are still not available. It should be noted that many of the factors involved in the hypercoagulability state of MetS are not significantly affected by acetylsalicylic acid and, therefore, its benefit cannot be assumed. In addition, no specific intervention studies have been conducted in this population, and thus data on the usefulness of aspirin therapy in patients with MetS are limited. Antiplatelet therapy with aspirin is a well-established treatment for the prevention of coronary events in patients with acute or chronic ischemic heart disease with or without T2DM. ${ }^{96}$ Therefore, aspirin should be recommended in patients with MetS in secondary prevention. By contrast, the CV benefits of antiplatelet therapy in primary prevention are scant and partially offset by the risk of bleeding, even when used in patients with risk factors such as diabetes or hypertension. ${ }^{97}$

\section{Recommendations}

The main clinical control recommendations for each component of MetS are shown in Table 5.

\section{Abdominal obesity}

Abdominal obesity defined by a high waist circumference according to sex and ethnicity ( $\geq 94 \mathrm{~cm}$ in Caucasian males and $\geq 80 \mathrm{~cm}$ in Caucasian females) and MetS are two closely related complex entities whose coexistence has become a serious health problem owing to an increase in the risk of CVD or T2DM. This situation has forced us to propose effective prevention and treatment strategies.

\section{Treatment}

Physical exercise and a healthy diet are the therapeutic pillars against obesity. MetS patients' control of their caloric intake is a fundamental part of their treatment, since weight loss of $5 \%-10 \%$, particularly if there is a preexisting overweight or obesity, notably improves glycemic control, lipid profile, and blood pressure. In addition, the nutritional quality of their diet must be improved, replacing foods with a greater diabetogenic and atherogenic effect by those who are more $\mathrm{CV}$ healthy. Reducing the saturated fat intake of daily calories by $<10 \%$, eliminating foods containing trans fatty acids, lower salt consumption, not consuming products with added sugar or other refined foods, consuming food with low glycemic carbohydrates - which will enhance fiber consumption by up to at least $15 \mathrm{~g} / 1,000 \mathrm{kcal}-$ and prioritizing specific food that are rich in nutrients such as legumes, whole grains, nuts, vegetables, and fruit are recommended as following these instructions has been found to correlate with a reduced CV risk. ${ }^{98}$ The Mediterranean diet model serves to guide patients with MetS and help control their CV risk. ${ }^{99}$ DASH or vegetarian diets, emphasizing the consumption of fruits, vegetables, legumes, and fish and limiting or reducing meats and saturated fats, are dietary patterns low in saturated fatty acids, cholesterol, and sodium and high in fiber, potassium, and unsaturated fatty acids, which have been shown to be beneficial for these patients by reducing $\mathrm{CV}$ risk. ${ }^{100,101}$

IR is a common feature of obesity and MetS. For this reason, increasing insulin sensitivity has been shown to be effective in improving the control of certain MetS components (blood pressure, HDL cholesterol, triglycerides, and glycemia). Weight loss or certain medications, such as metformin, may increase insulin sensitivity. Furthermore, currently certain drugs are approved by the European Medicines Agency, such as orlistat, the combination of naltrexone + bupropion, and liraglutide, which facilitate effective weight loss. ${ }^{102,103}$

Bariatric surgery is also an effective therapeutic option in morbidly obese patients or in those with a lower degree of obesity but who have associated CV risk factors. ${ }^{104}$ In addition, each anomaly associated with obesity and/or MetS should be addressed per individual, such as encouraging the patient to carry out regular physical exercise and give up smoking and alcohol consumption.

In summary, evidence showing that a high proportion of adults in developed societies present obesity and MetS, with a consequent increase in the risk of developing T2DM and CVD in the short/medium term exists. Lifestyle, especially physical exercise and diet, is the fundamental pillar of treatment which must include a weight loss of 5\%, mainly in overweight or obese patients, in order to improve glycemic control, lipid profile, and blood pressure levels. 
Table 5 Therapeutic goals and clinical control of the metabolic syndrome

\begin{tabular}{|c|c|c|}
\hline Component & Therapeutic objective & Observations \\
\hline $\begin{array}{l}\text { Abdominal } \\
\text { obesity }\end{array}$ & $\begin{array}{l}\text { Achieve a } 5 \%-10 \% \text { weight loss and carry out an aerobic } \\
\text { physical activity program that includes at least } 30-60 \\
\text { minutes a day of exercise adapted to the physical } \\
\text { condition of the individual }\end{array}$ & $\begin{array}{l}\text { Promote physical exercise and adopting a healthy diet such as the } \\
\text { Mediterranean, DASH, or vegetarian diets } \\
\text { Avoid a sedentary lifestyle }\end{array}$ \\
\hline $\begin{array}{l}\text { Fasting blood } \\
\text { glucose }\end{array}$ & $\begin{array}{l}\text { Basal glycemia }<100 \mathrm{mg} / \mathrm{dL} \text { in patients without diabetes. } \\
\text { If there is already a diagnosis of diabetes, the fasting } \\
\text { blood glucose target should be personalized given } \\
\text { that, similar to } \mathrm{HbA}_{\mathrm{Ic}} \text {, the objective will depend on the } \\
\text { existence of comorbidities and the risk of hypoglycemia, } \\
\text { among others }\end{array}$ & $\begin{array}{l}\text { In patients with prediabetes, a change of lifestyle is necessary - } \\
\text { personalized diet and physical activity plan. The use of metformin } \\
\text { can be considered in patients with impaired basal glycemia or } \\
\text { glucose intolerance, who also have a BMI }>35 \mathrm{~kg} / \mathrm{m}^{2} \text {, aged }<60 \\
\text { years, or are female with prior gestational diabetes } \\
\text { In patients with T2DM, metformin is the drug of choice. } \\
\text { When adding more drugs is necessary (HbA } \text { If }_{\text {Iflls outside the }} \\
\text { personalized target), those with a low risk of hypoglycemia are } \\
\text { recommended (DPP4i, SGLT2i, GLP-I receptor agonists), with } \\
\text { the first choice being SGLT2i and/or GLP-I receptor agonists in } \\
\text { cases of obesity } \\
\text { When CVD is already present, using SGLT2i (empagliflozin, } \\
\text { canagliflozin) or GLP-I receptor agonists (liraglutide) is } \\
\text { recommended }\end{array}$ \\
\hline $\mathrm{BP}$ & $\begin{array}{l}\text { Reduce } \mathrm{BP} \text { to }<140 / 90 \mathrm{mmHg} \text { in all patients. In high-risk } \\
\text { patients, a target }<130 / 80 \mathrm{mmHg} \text { may be recommended } \\
\text { if it is well tolerated }\end{array}$ & $\begin{array}{l}\text { Drugs that block RAS and calcium antagonists have a neutral or } \\
\text { favorable profile on lipid and hydrocarbon metabolism and are } \\
\text { recommended as first choice provided there are no other specific } \\
\text { indications or contraindications }\end{array}$ \\
\hline Lipids & $\begin{array}{l}\mathrm{LDL} \text { cholesterol } \leq 100 \mathrm{mg} / \mathrm{dL} \text { ( } \leq 70 \mathrm{mg} / \mathrm{dL} \text { in very high-risk } \\
\text { patients) } \\
\text { Non-HDL cholesterol } \leq 130 \mathrm{mg} / \mathrm{dL} \text { ( } \leq 100 \mathrm{mg} / \mathrm{dL} \text { in very } \\
\text { high-risk patients) } \\
\text { Triglycerides } \leq 150 \mathrm{mg} / \mathrm{dL} \\
\mathrm{HDL} \text { cholesterol } \geq 40 / 50 \mathrm{mg} / \mathrm{dL} \text { (male/female) }\end{array}$ & $\begin{array}{l}\text { The desirable level of LDL cholesterol or non-HDL cholesterol } \\
\text { depends on the patients' CV risk. To achieve targets in very high- } \\
\text { risk patients, a high-potency statin and dose should be selected } \\
\text { (atorvastatin } 40-80 \mathrm{mg} \text {, pitavastatin } 2-4 \mathrm{mg} \text {, or rosuvastatin } \\
20-40 \mathrm{mg} \text { ). In the presence of prediabetes, polypharmacy or } \\
\text { pluripathology, including renal failure, consider the use of a statin } \\
\text { such as pitavastatin that does not alter hydrocarbon metabolism } \\
\text { or that has a favorable interaction and safety profile, respectively } \\
\text { If an excess of LDL cholesterol or non-HDL cholesterol persists, } \\
\text { consider associating with ezetimibe } \\
\text { If hypertriglyceridemia persists, once the LDL cholesterol is } \\
\text { controlled, but non-HDL cholesterol is out of goals, consider the } \\
\text { addition of a fibrate (fenofibrate) }\end{array}$ \\
\hline
\end{tabular}

Abbreviations: CV, cardiovascular; CVD, cardiovascular disease; BP, blood pressure; RAS, renin angiotensin system; BMI, body mass index; LDL, low-density lipoprotein; HDL, high-density lipoprotein; DASH, dietary approaches to stop hypertension.

\section{Hyperglycemia/diabetes}

An OGTT (75 g) and $\mathrm{HbA}_{1 \mathrm{c}}$ should be requested for patients with MetS who do not meet diabetes criteria (see increased risk categories for diabetes). Considering the presence or absence of hyperglycemia to establish the patients' CV risk is recommended.

\section{Treatment}

A CV healthy lifestyle is essential for correct hyperglycemia and IR control and, consequently, all components of the MetS. A diet with a low content of rapidly digestible, simple carbohydrates, and high fiber content is sufficient to control hyperglycemia. ${ }^{29}$ Following a Mediterranean, diet has also been shown to reduce the occurrence of diabetes in at-risk individuals. ${ }^{105} \mathrm{~A} 7 \%$ loss of initial body weight and an increase in moderate physical activity (such as brisk walking) of at least 150 minutes/week can prevent the development of diabetes in predisposed individuals. ${ }^{30}$ Furthermore, data also demonstrate that resistance/strength exercises together with aerobic exercise are even more effective in preventing diabetes. ${ }^{106}$

The routine use of an antidiabetic drug is not recommended in patients with MetS/prediabetes. However, preventive treatment with metformin can be considered in cases with IFT, IGT, or an $\mathrm{HbA}_{1 \mathrm{c}}$ level of $5.7 \%-6.4 \%$, particularly if they have a BMI $>35 \mathrm{~kg} / \mathrm{m}^{2}$, are aged $<60$ years, and are females with prior gestational diabetes. ${ }^{38}$

In patients with MetS and liver steatosis, the use of pioglitazone could be relevant and, in those with a diagnosis of diabetes mellitus, insulin-sensitizing antidiabetics such 
as metformin and glitazones (pioglitazone) are basic in the treatment of T2DM with MetS.

Similarly, GLP-1 receptor agonists and SGLT-2 inhibitors, accompanied by significant weight loss, should be seriously considered. Patients with T2DM and CVD should be treated with antidiabetics with clearly demonstrated CV benefits such as empagliflozin, liraglutide, and canagliflozin. ${ }^{31-33}$

Bariatric surgery can be considered in cases with a BMI $>40$ or $>35 \mathrm{~kg} / \mathrm{m}^{2}$ plus comorbidities related to excess weight. ${ }^{104}$

\section{Arterial hypertension}

The general recommendation for all hypertensive patients with MetS is to make healthy changes in their lifestyle such as losing weight by limiting caloric intake and increasing physical exercise as well as reducing salt consumption. ${ }^{39-41}$ In addition, hypertensive patients with MetS should receive pharmacological treatment aimed at reducing blood pressure to levels $<140 / 90 \mathrm{mmHg}$. Recommendations for a more intense reduction ( $<130 \mathrm{mmHg}$ of SBP), based on the results emerging from the SPRINT study, ${ }^{42}$ could be applied to hypertensive patients with MetS - who have a high CV risk, according to the Framingham algorithm or CVD - but who do not have T2DM or a history of stroke.

\section{Treatment}

Except for specific indications of other therapeutic options or contraindications, when choosing pharmacological treatment, drugs that inhibit the renin-angiotensin system (ACEI and ARB-2) should be prioritized owing to their neutral or favorable effects on metabolic alterations. We should remember that the majority of patients with hypertension and MetS will require combination therapy to achieve blood pressure goals. In these cases, the combination of choice is a reninangiotensin system blocker with a calcium channel blocker.

\section{Dyslipidemia}

The pharmacological treatment of dyslipidemia in patients with MetS must be carried out with the following considerations:

1. Always rule out secondary causes of dyslipidemia, either hypercholesterolemia or hypertriglyceridemia.

2. Treat in parallel to the existing risk factors. Atherogenic dyslipidemia may be particularly influenced by the degree of hydrocarbon metabolic control.

3. Address LDL-dependent and non-LDL-dependent dyslipidemia in both therapeutic objectives and follow-up.
4. Optimize measures aimed at appropriately modifying lifestyle, which will have to be intense and continuous even when pharmacological treatment in monotherapy or combination is necessary.

The primary objective is to achieve the LDL cholesterol target. To do so:

1. Adjust treatment according to basal concentration and the reduction necessary to reach the therapeutic target.

2. Select the lipid-lowering drug and dose required to achieve the LDL cholesterol target. Clinical guidelines recommend the initial use of statins and titrates up to the maximum tolerable dose, if necessary.

3. Use, if needed, combination treatment when monotherapy is insufficient, there is intolerance to the statin, or to reduce the chances of adverse effects by using an average statin dose in addition to another hypocholesterolemiant (ezetimibe, resin, or PCSK9 inhibitor).

However, despite conventional or optimal treatment focused on achieving LDL cholesterol targets, non-LDLdependent dyslipidemia frequently persists, referred by a rise in triglycerides, a drop in HDL cholesterol and an increase in small and dense LDL particles. This triad, known as atherogenic dyslipidemia, includes certain components that comprise the diagnostic criteria for MetS. In this context, the SEA recommends that once LDL cholesterol has been controlled, the persistence of an atherogenic dyslipidemia results in an evaluation of treatment with a fibrate, either in monotherapy or as an additional treatment to the statin. ${ }^{82}$

Possible interactions should be considered in cases of statin + fibrate combination treatment. Here, fenofibrate is the fibrate of choice to prevent the adverse effects of the statin + gemfibrozil association. ${ }^{107}$

With respect to low HDL cholesterol, given the disappointing efficacy results of clinical outcome studies with extended release of niacin or cholesteryl ester transfer protein inhibitors in addition to statin therapy, these drugs have failed as combination therapy with statins in lipidtargeted approaches to reduce major cardiovascular events further in high-risk patients. For this reason, the majority of international clinical guidelines for the management of dyslipidemia or CVD prevention do not consider HDL cholesterol a therapeutic goal. ${ }^{18,19,28,75}$ However, the beneficial effects of lifestyle changes, as well as statins and fibrates in raising HDL cholesterol concentrations should be taken into account. 18,19,22,60,68 


\section{Antiaggregation}

For secondary prevention, the CV benefits of antiplatelet therapy with aspirin are well known. For this reason, all patients with MetS and CVD in any location should be treated with aspirin at low doses.

The best recommendation for the use of aspirin therapy in primary prevention is to follow current guidelines that attempt to balance the risks and benefits of this therapeutic strategy. ${ }^{108-110}$ In this respect, the potential bleeding risk should be borne in mind when considering aspirin therapy in primary prevention. In general, clinical guidelines recommend the use of aspirin in patients with a 10 -year CV risk $>10 \%$, provided there are no contraindications. In clinical situations with a contraindication or resistance to aspirin, omega-3 fatty acids $(2,800 \mathrm{mg})$ are a reasonable alternative to low-dose aspirin. ${ }^{11}$

\section{Conclusion}

In summary, MetS, a recognized risk factor for CVD and T2DM is unfortunately underrecognized, undertreated, and consequently undercontrolled. Its management is highly heterogeneous, which can hamper clinical decision-making and be a barrier to achieving the therapeutic goals for CVD and diabetes prevention. The treatment of MetS represents a growing, unmet therapeutic need in the CVD and diabetes prevention scenario. Although no single treatment for MetS as a whole currently exists, management should be targeted at treating the conditions contributing to it and possibly reversing the risk factors. In the present consensus document, professionals from different scientific societies involved in the management of different MetS components, reviewed the available scientific evidence focused basically on therapeutic aspects, and established recommendations on therapeutic goals that facilitate homogenization in clinical decision-making. In this respect, the cornerstone therapeutic approach is lifestyle intervention, particularly weight reduction and physical activity, which can reverse the metabolic risk factors. However, pharmacological therapies may frequently be required to control more overt risk factors such as dyslipidemia and hypertension. Further clinical trials on the safety and efficacy of novel therapies for this condition, as well as better designed clinical trials of existing therapies such as fibrates, are awaited.

\section{Disclosure}

The authors report no conflicts of interest in this work.

\section{References}

1. Ascaso JF, González-Santos P, Hernández-Mijares A, et al. Diagnosis of metabolic syndrome. Adaptation of diagnostic criteria in our setting. Recommendations of the HDL forum. Rev Clin Esp. 2006;206:576-582.
2. Third Report of the National Cholesterol Education Program (NCEP) Expert Panel on Detection, Evaluation, and Treatment of High Blood Cholesterol in Adults (Adult Treatment Panel III). Final report. Circulation. 2002;106:3143-3421.

3. Grundy SM, Cleeman JI, Daniels SR, et al. Diagnosis and management of the metabolic syndrome: an American Heart Association/National Heart, Lung, and Blood Institute Scientific Statement. Circulation. 2005;112:2735-2752.

4. Alberti KG, Zimmet P, Shaw J. Metabolic syndrome: a new worldwide definition. A consensus statement from the International Diabetes Federation. Diabet Med. 2006;23:469-480.

5. Alberti KG, Eckel RH, Grundy SM, et al. Harmonizing the metabolic syndrome: a Joint Interim Statement of the International Diabetes Federation Task Force on Epidemiology and Prevention; National Heart, Lung, and Blood Institute; American Heart Association; World Heart Federation; International Atherosclerosis Society; and International Association for the Study of Obesity. Circulation. 2009;120:1640-1645.

6. Estudio Valencia: investigación de la prevalencia de diabetes mellitus y síndrome metabólico. Plan de Diabetes de la Comunitat Valenciana 2006-10. Generalitat Valenciana. Conselleria de Sanitat 2010. Available from: http://publicaciones.san.gva.es/publicaciones/ documentos/V.2672-2010.pdf. Accessed August 24, 2018.

7. Mottillo S, Filion KB, Genest J, et al. The metabolic syndrome and cardiovascular risk a systematic review and meta-analysis. $\mathrm{J} \mathrm{Am} \mathrm{Coll}$ Cardiol. 2010;56:1113-1132.

8. Wilson PW, D'Agostino RB, Parise H, Sullivan L, Meigs JB. Metabolic syndrome as a precursor of cardiovascular disease and type 2 diabetes mellitus. Circulation. 2005;112:3066-3072.

9. Ford ES, Li C, Sattar N. Metabolic syndrome and incident diabetes: current state of the evidence. Diabetes Care. 2008;31:1898-1904.

10. Shin JA, Lee JH, Lim SY, et al. Metabolic syndrome as a predictor of type 2 diabetes, and its clinical interpretations and usefulness. J Diabetes Invest. 2013;4:334-343.

11. Flint TR, Fearon DT, Janowitz T. Connecting the metabolic and immune responses to cancer. Trends Mol Med. 2017;23:451-464.

12. Lahoz C, Vicente I, Laguna F, García-Iglesias MF, Taboada M, Mostaza JM. Metabolic syndrome and asymptomatic peripheral artery disease in subjects over 60 years of age. Diabetes Care. 2006;29:148-150.

13. Klein BE, Klein R, Lee KE. Components of the metabolic syndrome and risk of cardiovascular disease and diabetes in Beaver Dam. Diabetes Care. 2002;25:1790-1794.

14. Girman CJ, Rhodes T, Mercuri M, et al. The metabolic syndrome and risk of major coronary events in the Scandinavian Simvastatin Survival Study (4S) and the Air Force/Texas Coronary Atherosclerosis Prevention Study (AFCAPS/TexCAPS). Am J Cardiol. 2004;93:136-141.

15. Deedwania P, Barter P, Carmena R, et al. Reduction of low-density lipoprotein cholesterol in patients with coronary heart disease and metabolic syndrome: analysis of the Treating to New Targets study. Lancet. 2006;368:919-928.

16. Scott R, Donoghoe M, Watts GF, et al. Impact of metabolic syndrome and its components on cardiovascular disease event rates in 4900 patients with type 2 diabetes assigned to placebo in the field randomised trial. Cardiovasc Diabetol. 2011;10:102.

17. de Simone G, Devereux RB, Chinali M, et al. Prognostic impact of metabolic syndrome by different definitions in a population with high prevalence of obesity and diabetes: the Strong Heart Study. Diabetes Care. 2007;30:1851-1856.

18. Piepoli MF, Hoes AW, Agewall S, et al. 2016 European Guidelines on cardiovascular disease prevention in clinical practice: The Sixth Joint Task Force of the European Society of Cardiology and Other Societies on Cardiovascular Disease Prevention in Clinical Practice (constituted by representatives of 10 societies and by invited experts) developed with the special contribution of the European Association for Cardiovascular Prevention \& Rehabilitation (EACPR). Eur Heart J. 2016;37:2315-2381. 
19. Catapano AL, Graham I, De Backer G, et al. 2016 ESC/EAS Guidelines for the management of dyslipidaemias: The Task Force for the Management of Dyslipidaemias of the European Society of Cardiology (ESC) and European Atherosclerosis Society (EAS) Developed with the special contribution of the European Association for Cardiovascular Prevention \& Rehabilitation (EACPR). Atherosclerosis. 2016;253:281-344.

20. Teixeira TF, Alves RD, Moreira AP, Peluzio Mdo C. Main characteristics of metabolically obese normal weight and metabolically healthy obese phenotypes. Nutr Rev. 2015;73:175-190.

21. Lioudaki E, Vrentzos GE, Mavrogeni H, et al. Prevalence of metabolic syndrome according to different definitions in a hypertensive population. Angiology. 2012;63:39-47.

22. Perez-Martinez P, Mikhailidis DP, Athyros VG, et al. Lifestyle recommendations for the prevention and management of metabolic syndrome: an international panel recommendation. Nutr Rev. 2017;75:307-326.

23. Stern MP, Williams K, González-Villalpando C, Hunt KJ, Haffner S. Does the metabolic syndrome improve identification of individuals at risk of type 2 diabetes and/or cardiovascular disease? Diabetes Care. 2004;27:676-681.

24. Ascaso JF, Romero P, Real JT, Lorente RI, Martínez-Valls J, Carmena R. Abdominal adiposity (waist circumference) and its relation to insulin resistance and the metabolic syndrome in a South European population. Eur J Intern Med. 2003;14:101-106.

25. Standards of Medical Care in Diabetes-2017. Classification and diagnosis of diabetes. Diabetes Care. 2017;40(Suppl 1):S11-S24.

26. Dagenais GR, St-Pierre A, Gilbert P, et al. Comparison of prognosis for men with type 2 diabetes mellitus and men with cardiovascular disease. CMAJ. 2009;180:40-47.

27. Sattar N. Revisiting the links between glycaemia, diabetes and cardiovascular disease. Diabetologia. 2013;56:686-695.

28. Jellinger PS, Handelsman Y, Rosenblit PD, et al. American Association of Clinical Endocrinologists and American College of Endocrinology guidelines for management of dyslipidemia and prevention of atherosclerosis. Endocr Pract. 2017;23(Suppl 2):1-87.

29. De Natale C, Annuzzi G, Bozzetto L, et al. Effects of a plant-based high-carbohydrate/high-fiber diet versus high-monounsaturated fat/ low-carbohydrate diet on postprandial lipids in type 2 diabetic patients. Diabetes Care. 2009;32:2168-2173.

30. Knowler WC, Barrett-Connor E, Fowler SE, et al; Diabetes Prevention Program Research Group. Reduction in the incidence of type 2 diabetes with lifestyle intervention or metformin. $N$ Engl J Med. 2002;346:393-403.

31. Zinman B, Wanner C, Lachin JM, et al; EMPAREG OUTCOME Investigators. Empagliflozin, cardiovascular outcomes, and mortality in type 2 diabetes. N Engl J Med. 2015;373:2117-2128.

32. Marso SP, Daniels GH, Brown-Frandsen K, et al; LEADER Steering Committee; LEADER Trial Investigators. Liraglutide and cardiovascular outcomes in type 2 diabetes. $N$ Engl J Med. 2016;375: 311-322.

33. Neal B, Perkovic V, Mahaffey KW, et al; for the CANVAS Program Collaborative Group. Canagliflozin and cardiovascular and renal events in type 2 diabetes. $N$ Engl J Med. 2017;377:644-657.

34. DeFronzo RA, Tripathy D, Schwenke DC, et al. Pioglitazone for diabetes prevention in impaired glucose tolerance. $N$ Engl J Med. 2011;364:1104-1115.

35. Cusi K, Orsak B, Bril F, et al. Long-term pioglitazone treatment for patients with nonalcoholic steatohepatitis and prediabetes or type 2 diabetes mellitus: a randomized trial. Ann Intern Med. 2016;165: 305-315.

36. Le Roux CW, Astrup A, Fujioka K, et al. 3 Years of liraglutide versus placebo for type 2 diabetes risk reduction and weight management in individuals with prediabetes: a randomised, double-blind trial. Lancet. 2017;389:1399-1409.

37. Pi-Sunyer X, Astrup A, Fujioka K, et al. A randomized, controlled trial of $3.0 \mathrm{mg}$ of liraglutide in weight management. $N$ Engl J Med. 2015;373:11-22.
38. American Diabetes Association. Prevention or delay of type 2 diabetes. Diabetes Care. 2017;40(Suppl 1):S44-S47.

39. Mancia G, Fagard R, Narkiewicz K, et al. 2013 ESH/ESC guidelines for the management of arterial hypertension. J Hypertens. 2013;31:1281-1357.

40. James PA, Oparil S, Carter BL, et al. 2014 evidence-based guideline for the management of high blood pressure in adults: report from the panel members appointed to the Eighth Joint National Committee (JNC 8). JAMA. 2014;311:507-520.

41. Weber MA, Schiffrin EL, White WB, et al. Clinical practice guidelines for the management of hypertension in the community a statement by the American Society of Hypertension and the International Society of Hypertension. J Hypertens. 2014;32:3-15.

42. SPRINT Research Group, Wright JT Jr, Williamson JD, Whelton PK, et al. A randomized trial of intensive versus standard blood-pressure control. N Engl J Med. 2015;373:2103-2116.

43. Whelton PK, Carey RM, Aronow WS, et al. 2017 ACC/AHA/AAPA/ ABC/ACPM/AGS/APhA/ASH/ASPC/NMA/PCNA guideline for the prevention, detection, evaluation, and management of high blood pressure in adults: a report of the American College of Cardiology/ American Heart Association Task Force on Clinical Practice. Hypertension. 2018;71:e13-e115.

44. NAVIGATOR Study Group, McMurray JJ, Holman RR, Haffner SM, et al. Effect of valsartan on the incidence of diabetes and cardiovascular events. N Engl J Med. 2010;362:1477-1490.

45. Taskinen MR, Boren J. New insights into the pathophysiology of dyslipidemia in type 2 diabetes. Atherosclerosis. 2015;239:483-495.

46. The Emerging Risk Factors Collaboration. Major lipids, apolipoproteins, and risk of vascular disease. JAMA. 2009;302:1993-2000.

47. Holmes MV, Ala-Korpela M, Smith GD. Mendelian randomization in cardiometabolic disease: challenges in evaluating causality. Nat Rev Cardiol. 2017;14:577-590.

48. HPS3/TIMI55-REVEAL Collaborative Group. Effects of anacetrapib in patients with atherosclerotic vascular disease. $N$ Engl J Med. 2017;377:1217-1227.

49. Nordestgaard BG. Triglyceride-rich lipoproteins and atherosclerotic cardiovascular disease: new insights from epidemiology, genetics, and biology. Circ Res. 2016;118:547-563.

50. Chapman MJ, Ginsberg HN, Amarenco P, et al. Triglyceride-rich lipoproteins and high-density lipoprotein cholesterol in patients at high risk of cardiovascular disease: evidence and guidance for management. Eur Heart J. 2011;32:1345-1361.

51. Nordestgaard BG, Chapman MJ, Ray K, et al. Lipoprotein(a) as a cardiovascular risk factor: current status. Eur Heart J. 2010;1:2844-2853.

52. Vaverkova H, Karasek D, Halenka M, Cibickova L, Kubickova V. Inverse association of lipoprotein(a) with markers of insulin resistance in dyslipidemic subjects. Physiol Res. 2017;66:S113-S120.

53. Vonbank A, Saely CH, Rein P, Zanolin D, Drexel H. Lipoprotein(a), the metabolic syndrome and vascular risk in angiographied coronary patients. J Clin Endocrinol Metab. 2016;101:3199-3203.

54. Pedro-Botet J, Badimon L. PCSK9: structure and function. PCSK9 and low-density lipoprotein receptor. Mutations and their effects. Clin Investig Arterioscler. 2016;28(Suppl 2):3-8.

55. Guardiola M, Plana N, Ibarretxe D, et al. Circulating PCSK9 levels are positively correlated with NMR-assessed atherogenic dyslipidaemia in patients with high cardiovascular risk. Clin Sci (Lond). 2015;128:877-882.

56. Ibarretxe D, Girona J, Plana N, et al. Circulating PCSK9 in patients with type 2 diabetes and related metabolic disorders. Clin Investig Arterioscler. 2016;28:71-78.

57. Richard C, Couture P, Desroches S, et al. Effect of the Mediterranean diet with and without weight loss on surrogate markers of cholesterol homeostasis in men with the metabolic syndrome. Br J Nutr. 2012;107:705-711.

58. Grundy SM. Metabolic syndrome update. Trends Cardiovasc Med. 2016;26:364-373. 
59. Sniderman AD, St-Pierre A, Cantin B, Dagenais GR, Depres J-P, Lamarche B. Concordance/discordance between plasma apolipoprotein $\mathrm{B}$ levels and the cholesterol indexes of atherosclerotic risk. Am J Cardiol. 2003;91:1173-1177.

60. Expert Dyslipidemia Panel of the International Atherosclerosis Society Panel members. An International Atherosclerosis Society position paper: global recommendations for the management of dyslipidemia - full report. J Clin Lipidol. 2014;8:29-60.

61. Marcovina SM, Albers JJ, Kennedy H, Mei JV, Henderson LO, Hannon WH. International Federation of Clinical Chemistry standardization project for measurements of apolipoproteins A-I and B. IV. Comparability of apolipoprotein $\mathrm{B}$ values by use of international reference material. Clin Chem. 1994;40:586-592.

62. Ballantyne CM, Raichlen JS, Cain VA. Statin therapy alters the relationship between apolipoprotein $\mathrm{B}$ and low-density lipoprotein cholesterol and non-high-density lipoprotein cholesterol targets in high-risk patients: the MERCURY II (Measuring Effective Reductions in Cholesterol Using Rosuvastatin) trial. $J$ Am Coll Cardiol. 2008;52:626-632.

63. Pedro-Botet J, Pintó X. An updated overview of the high intensity lipid lowering therapy in high cardiovascular risk patients. Clin Investig Arterioscler. 2016;28:19-30.

64. Lee ET, Howard BV, Wang W, et al. Prediction of coronary heart disease in a population with high prevalence of diabetes and albuminuria: the Strong Heart Study. Circulation. 2006;113:2897-2905.

65. Baigent C, Keech A, Kearney PM, et al; Cholesterol Treatment Trialists' (CTT) Collaborators. Efficacy and safety of cholesterol-lowering treatment: prospective meta-analysis of data from 90,056 participants in 14 randomised trials of statins. Lancet. 2005;366:1267-1278.

66. Rubenfire M, Brook RD, Rosenson RS. Treating mixed hyperlipidemia and the atherogenic lipid phenotype for prevention of cardiovascular events. Am J Med. 2010;123:892-898.

67. Bosomworth NJ. Approach to identifying and managing atherogenic dyslipidemia. A metabolic consequence of obesity and diabetes. Can Fam Physician. 2013;59:1169-1180.

68. Jacobson TA, Ito MK, Maki KC, et al. National Lipid Association recommendations for patient-centered management of dyslipidemia: part 1-full report. J Clin Lipidol. 2015;9:129-169.

69. Pyörälä K, Ballantyne CM, Gumbiner B, et al. Reduction of cardiovascular events by simvastatin in nondiabetic coronary heart disease patients with and without the metabolic syndrome: subgroup analyses of the Scandinavian Simvastatin Survival Study (4S). Diabetes Care. 2004;27:1735-1740.

70. Matsushima T, Nakaya N, Mizuno K, et al. The effect of low-dose pravastatin in metabolic syndrome for primary prevention of cardiovascular disease in Japan: a post hoc analysis of the MEGA study. J Cardiovasc Pharmacol Ther. 2012;17:153-158.

71. Sniderman AD, Furberg CD, Keech A, et al. Apolipoproteins versus lipids as indices of coronary risk and as targets for statin treatment. Lancet. 2003;361:777-780.

72. Stein EA, Sniderman A, Laskarzewski P. Assessment of reaching goal in patients with combined hyperlipidemia: low-density lipoprotein cholesterol, non-high-density lipoprotein cholesterol, or apolipoprotein B. Am J Cardiol. 2005;96:36K-43K.

73. Ballantyne CM, Bertolami M, Hernandez Garcia HR, et al. Achieving LDL cholesterol, non-HDL cholesterol, and apolipoprotein B target levels in high-risk patients: Measuring Effective Reductions in Cholesterol Using Rosuvastatin therapy (MERCURY) II. Am Heart J. 2006;151:975-983.

74. Salas-Salvadó J, Guasch-Ferré M, Estruch R, Clish CB, Ros E. Protective effects of the Mediterranean diet on type 2 diabetes and metabolic syndrome. J Nutr. 2016;146(Suppl):920S-927S.

75. Stone NJ, Robinson J, Lichtenstein AH, et al. 2013 ACC/AHA guideline on the treatment of blood cholesterol to reduce atherosclerotic cardiovascular risk in adults: a report of the American College of Cardiology/American Heart Association Task Force on Practice Guidelines. J Am Coll Cardiol. 2014;63:2889-2934.
76. Rosen JB, Ballantyne CM, Hsueh WA, et al. Influence of metabolic syndrome factors and insulin resistance on the efficacy of ezetimibe/ simvastatin and atorvastatin in patients with metabolic syndrome and atherosclerotic coronary heart disease risk. Lipids Health Dis. 2015; $14: 103$

77. Brinton EA, Maki KC, Jacobson TA, Sponseller CA, Cohen JD. Metabolic syndrome is associated with muscle symptoms among statin users. J Clin Lipidol. 2016;10:1022-1029.

78. Hoy SM. Pitavastatin: a review in hypercholesterolemia. Am J Cardiovasc Drugs. 2017;17:157-168.

79. Pintó X, Trias Vilagut F, Rius Taruella J, Mairal Sallán E. Dyslipidemia management in patients with high cardiovascular risk in Spain. ALMA study. Aten Primaria. 2018;50:35-43.

80. Pedro-Botet J, Barrios V, Pascual V, et al. Delphi consensus on management of dyslipidaemia in patients with impaired glucose metabolism: Diana study. Clin Investig Arterioscler. 2016;28:132-140.

81. Masana L, Ascaso JF, Civeira F, et al; Sociedad Española de Arteriosclerosis. Consensus document of the Spanish Society of Arteriosclerosis on indications of inhibitors of PCSK9. Clin Investig Arterioscler. 2016;28:164-165.

82. Ascaso JF, Millán J, Hernández-Mijares A, et al. Consensus document on the management of the atherogenic dyslipidaemia of the Spanish Society of Arteriosclerosis. Clin Investig Arterioscler. 2017;29: 86-91.

83. Jakob T, Nordmann AJ, Schandelmaier S, Ferreira-González I, Briel M. Fibrates for primary prevention of cardiovascular disease events. Cochrane Database Syst Rev. 2016;11:CD009753.

84. Wang D, Liu B, Tao W, Hao Z, Liu M. Fibrates for secondary prevention of cardiovascular disease and stroke. Cochrane Database Syst Rev. 2015;10:CD009580.

85. Anand SS, Yi Q, Gerstein H, et al; Study of Health Assessment and Risk in Ethnic Groups; Study of Health Assessment and Risk Evaluation in Aboriginal Peoples Investigators. Relationship of metabolic syndrome and fibrinolytic dysfunction to cardiovascular disease. Circulation. 2003;108:420-425.

86. Faber DR, de Groot PG, Visseren FL. Role of adipose tissue in haemostasis, coagulation and fibrinolysis. Obes Rev. 2009;10:554-563.

87. Alessi MC, Juhan-Vague I. Metabolic syndrome, haemostasis and thrombosis. Thromb Haemost. 2008;99:995-1000.

88. Kostapanos MS, Florentin M, Elisaf MS, Mikhailidis DP. Hemostatic factors and the metabolic syndrome. Curr Vasc Pharmacol. 2013;11:880-905.

89. Kraja AT, Province MA, Arnett D, et al. Do inflammation and procoagulation biomarkers contribute to the metabolic syndrome cluster? Nutr Metab (Lond). 2007;4:28.

90. Samad F, Ruf W. Inflammation, obesity, and thrombosis. Blood. 2013;122:3415-3422.

91. Rao AK, Freishtat RJ, Jalagadugula G, et al. Alterations in insulin-signaling and coagulation pathways in platelets during hyperglycemia-hyperinsulinemia in healthy non-diabetic subject. Thromb Res. 2014;134:704-710.

92. Ay C, Tengler T, Vormittag R, et al. Venous thromboembolism: a manifestation of the metabolic syndrome. Haematologica. 2007;92:374-380.

93. Elbatarny HS, Netherton SJ, Ovens JD, Ferguson AV, Maurice DH. Adiponectin, ghrelin, and leptin differentially influence human platelet and human vascular endothelial cell functions: implication in obesityassociated cardiovascular diseases. Eur J Pharmacol. 2007;558:7-13.

94. Vaduganathan M, Alviar CL, Arikan ME, et al. Platelet reactivity and response to aspirin in subjects with the metabolic syndrome. $\mathrm{Am}$ Heart J. 2008; 156:1002.

95. Bladbjerg EM, Larsen TM, Due A, Jespersen J, Stender S, Astrup A. Postprandial coagulation activation in overweight individuals after weight loss: acute and long-term effects of a high-monounsaturated fat diet and a low-fat diet. Thromb Res. 2014;133:327-333.

96. Antithrombotic Trialists' (ATT) Collaboration, Baigent C, Blackwell L, Collins R, et al. Aspirin in the primary and secondary prevention of vascular disease: collaborative meta-analysis of individual participant data from randomised trials. Lancet. 2009;373:1849-1860. 
97. Newman JD, Schwartzbard AZ, Weintraub HS, Goldberg IJ, Berger JS. Primary prevention of cardiovascular disease in diabetes mellitus. J Am Coll Cardiol. 2017;70:883-893.

98. Salas-Salvado J, Fernandez-Ballart J, Ros E, et al. Effect of a Mediterranean diet supplemented with nuts on metabolic syndrome status: one-year results of the PREDIMED randomized trial. Arch Intern Med. 2008;168:2449-2458.

99. Babio N, Toledo E, Estruch R, et al. Mediterranean diets and metabolic syndrome status in the PREDIMED randomized trial. CMAJ. 2014;186:E649-E657.

100. Tobias DK, Chen M, Manson JE, Ludwig DS, Willett W, Hu FB. Effect of low-fat diet interventions versus other diet interventions on longterm weight change in adults: a systematic review and meta-analysis. Lancet Diabetes Endocrinol. 2015;3:968-979.

101. Steffen LM, Van Horn L, Daviglus ML, et al. A modified Mediterranean diet score is associated with a lower risk of incident metabolic syndrome over 25 years among young adults: the CARDIA (Coronary Artery Risk Development in Young Adults) study. Br J Nutr. 2014;112:1654-1661.

102. Pucci A, Finer N. New medications for treatment of obesity: metabolic and cardiovascular effects. Can J Cardiol. 2015;31:142-152.

103. Mancini MC, de Melo ME. The burden of obesity in the current world and the new treatments available: focus on liraglutide $3.0 \mathrm{mg}$. Diabetol Metab Syndr. 2017;9:44.

104. Gloy VL, Briel M, Bhatt DL, et al. Bariatric surgery versus nonsurgical treatment for obesity: a systematic review and meta-analysis of randomised controlled trials. BMJ. 2013;347:f5934.

105. Salas-Salvadó J, Bulló M, Estruch R, et al. Prevention of diabetes with Mediterranean diets: a subgroup analysis of a randomized trial. Ann Intern Med. 2014;160:1-10.
106. Davy BM, Winett RA, Savla J, et al. Resist diabetes: a randomized clinical trial for resistance training maintenance in adults with prediabetes. PLoS One. 2017;12:e0172610.

107. Ferrari R, Aguiar C, Alegria E, et al. Current practice in identifying and treating cardiovascular risk, with a focus on residual risk associated with atherogenic dyslipidaemia. Eur Heart J Suppl. 2016;18(Suppl C): C2-C12.

108. US Preventive Services Task Force. Aspirin for the prevention of cardiovascular disease: U.S. Preventive Services Task Force recommendation statement. Ann Intern Med. 2009;150:396-404.

109. Pignone M, Alberts MJ, Colwell JA, et al; American Diabetes Association; American Heart Association; American College of Cardiology Foundation. Aspirin for primary prevention of cardiovascular events in people with diabetes: a position statement of the American Diabetes Association, a scientific statement of the American Heart Association, and an expert consensus document of the American College of Cardiology Foundation. Diabetes Care. 2010;33:1395-1402.

110. Goldstein LB, Bushnell CD, Adams RJ, et al; American Heart Association Stroke Council; Council on Cardiovascular Nursing; Council on Epidemiology and Prevention; Council for High Blood Pressure Research; Council on Peripheral Vascular Disease, and Interdisciplinary Council on Quality of Care and Outcomes Research. Guidelines for the primary prevention of stroke: a guideline for healthcare professionals from the American Heart Association/American Stroke Association. Stroke. 2011;42:517-584.

111. Lev EI, Solodky A, Harel N, et al. Treatment of aspirin-resistant patients with omega-3 fatty acids versus aspirin dose escalation. $\mathrm{JAm}$ Coll Cardiol. 2010;55:114-121.
Diabetes, Metabolic Syndrome and Obesity: Targets and Therapy is an international, peer-reviewed open-access journal committed to the rapid publication of the latest laboratory and clinical findings in the fields of diabetes, metabolic syndrome and obesity research. Original research, review, case reports, hypothesis formation, expert

\section{Dovepress}

opinion and commentaries are all considered for publication. The manuscript management system is completely online and includes a very quick and fair peer-review system, which is all easy to use. Visit http://www.dovepress.com/testimonials.php to read real quotes from published authors. 